\title{
Organizations, coalitions, and movements
}

\author{
MARIO DIANI and IVANO BISON \\ University of Trento and University of Strathclyde in Glasgow; University of Trento
}

\begin{abstract}
This article uses empirical evidence on networks of voluntary organizations mobilizing on ethnic minority, environmental, and social exclusion issues in two British cities, to differentiate between social movement processes and other, cognate collective action dynamics. Social movement processes are identified as the building and reproducing of dense informal networks between a multiplicity of actors, sharing a collective identity, and engaged in social and/or political conflict. They are contrasted to coalitional processes, where alliances to achieve specific goals are not backed by significant identity links, and organizational processes, where collective action takes place mostly in reference to specific organizations rather than broader, looser networks.
\end{abstract}

Among his innumerable contributions to the study of social movements, Charles Tilly has provided practitioners with what is probably the most popular definition of their object of analysis: "a sustained series of interactions between power-holders and persons successfully claiming to speak on behalf of a constituency lacking formal representation, in the course of which those persons make publicly visible demands for change in the distribution or exercise of power, and back those demands with public demonstrations of support." Recently, however, the reference to "social movements" has lost centrality in his analytical scheme. The "Dynamics of contention" program (henceforth "Doc") invokes a reorientation of the social movement research agenda toward the identification of mechanisms, which may be found to operate across highly different episodes and forms of contentious politics. ${ }^{2}$ Its advocates regard social movements as a particular form of political participation ${ }^{3}$ or, interchangeably, as broad episodes of contention - along with democratization, nationalism, and revolution - from the analysis of which we can extract specific social mechanisms. ${ }^{4}$

There are very good reasons not to treat "social movements" as a distinct set of phenomena, or to posit that there should be specific intellectual sub-fields devoted to their exclusive study. Indeed, the whole development of the field reflects recurrent cross-fertilization 
with neighboring areas of research, including the study of unions, voluntary action, nationalism, and many others. However, there are also risks attached to dispensing altogether with the concept of social movement, and focusing instead on other mechanisms and processes, such as individual recruitment, cultural production, or identitybuilding, ${ }^{5}$ which can contribute to our explanation of specific episodes of contention, conventionally called "social movements." Although we broadly sympathize with the mechanism-based approach, ${ }^{6}$ we argue that it is possible to refer to social movements as distinctive social processes in their own right rather than as "phenomena" or even "episodes."

In this article, we show how a network perspective differentiates social movements from other instances of collective action and campaigning. We start from a definition of social movements as "networks of informal interactions between a plurality of individuals, groups, or associations, engaged in a political or cultural conflict, on the basis of a shared collective identity."7 We use it to develop a typology of forms of collective action. We then illustrate its heuristic power through the analysis of networks of civic organizations in two British cities, Bristol and Glasgow. In particular, we search for different dynamics within networks of citizens' organizations in Bristol and Glasgow by going through the following steps: identify alliance patterns, i.e., the structure of collaborations among organizations at a given time; look for indicators of collective identity, by exploring the continuity of collaboration over time and the extent of mutual recognition, as reflected in overlapping memberships; assess the conflictual nature of the interactions taking place in the network. Throughout the article, we deliberately avoid any reference to organizations' substantive properties, and to the relation between such properties and network structures. Our interest here is focused on the identification of different network processes within specific local settings.

\section{Conflicts, networks, and identities}

We can capture important differences between social movement processes and other collective action processes - including adversarial coalitions, voluntary campaigns on widely shared collective goals, organizational action - by looking at social movements as a particular position in an analytical space defined by three dimensions:

- presence or absence of conflictual orientations to clearly identified opponents; 
- dense or sparse informal exchanges between individuals or organizations engaged in collective projects;

- strong or weak collective identity between members of those networks.

In particular, we see social movement processes as instances of collective action with clear conflictual orientations to specific social and political opponents, conducted in the context of dense inter-organizational networking, by actors linked by solidarities and shared identities that precede and survive any specific coalitions and campaigns. ${ }^{8}$ First, the experience of social movements is inextricably linked to the public expression of a social conflict. Not only is collective action oriented to address collective problems, redress injustices, achieve public goods, tackle sources of grievances, or express support to some moral values or principles; it does so by identifying targets for collective efforts, specifically articulated in social or political terms. Collective action may be associated with social movements (although not only with them) to the extent that it challenges the behavior or the legitimacy of specific social or political actors, not of single individuals or of the humankind taken as a whole, not to mention the attribution of the problems addressed by collective action to non-human causes, from natural disasters to divine will. ${ }^{9}$

Second, the presence of dense informal inter-organizational networks differentiates social movement processes from the innumerable instances in which collective action takes place and is coordinated mostly within the boundaries of specific organizations. ${ }^{10}$ A social movement process is in place to the extent that both individual and organized actors, while keeping their autonomy and independence, engage in sustained exchanges of resources in pursuit of common goals. The coordination of specific initiatives, the regulation of individual actors' conduct, and the definition of strategies are all dependent on permanent negotiations between the individuals and the organizations involved in collective action. No single organized actor, no matter how powerful, can claim to represent a movement as a whole. An important consequence of the role of network dynamics is that more opportunities arise for highly committed or skilled individuals to play an independent role in the political process, than would be the case when action is concentrated within formal organizations.

Finally, collective identity is essential inasmuch as a movement cannot be reduced to any specific event or campaign, nor to a specific 
coalition, no matter how big their profile and impact. Indeed, a social movement process is in place when collective identities develop that go beyond specific campaigns and initiatives. Collective identity is a process strongly associated with recognition and the creation of connectedness. ${ }^{11}$ It brings with it a sense of common purpose and shared commitment to a cause, which enables single activists and organizations to regard themselves as inextricably linked to other actors, not necessarily identical but surely compatible, in a broader collective mobilization. ${ }^{12}$ Collective identity also enables actors to establish connections among different occurrences, private and public, located at different points in time and space, which are relevant to their experience, and that might as well have been conceived of as largely independent from each other under different circumstances, and to weave them in broader, encompassing narratives. ${ }^{13}$ As a result, organizational and individual actors involved in collective action no longer merely pursue specific goals, but come to regard themselves as elements of much larger and encompassing processes of change - or resistance to change. Within social movement networks, membership criteria are extremely unstable and ultimately dependent on mutual recognition between actors; the activity of boundary definition - i.e., of defining who is and who is not part of the network - indeed plays a central role in the emergence and shaping of collective action. ${ }^{14}$

Looking at different combinations of the three properties listed above enables us to contrast social movements to other collective action processes. Here we focus on five ${ }^{15}$ of them (Table 1), keeping in mind that no empirical episode of collective action - those that we conventionally define as "environmental movements," "solidarity movements," "disabled movements," or the like - fully corresponds to any of the

Table 1. A typology of collective action processes

\begin{tabular}{llcc}
\hline $\begin{array}{l}\text { Dense vs. sparse } \\
\text { informal networks }\end{array}$ & $\begin{array}{l}\text { Network identity vs. } \\
\text { organizational identity }\end{array}$ & \multicolumn{2}{c}{$\begin{array}{c}\text { Conflictual vs. } \\
\text { consensual action }\end{array}$} \\
\hline & & $\begin{array}{c}\text { Conflictual } \\
\text { action }\end{array}$ & $\begin{array}{c}\text { Consensual } \\
\text { action }\end{array}$ \\
Dense informal & Strong network & Social & $\begin{array}{c}\text { Consensus } \\
\text { motworks }\end{array}$ \\
identity & movement & movement \\
Dense informal & Weak network & Conflict & Consensus \\
networks & identity & coalition & coalition \\
Sparse informal & Weak network & Conflict & Consensus \\
networks & identity & organization & organization \\
\hline
\end{tabular}


types presented here. In contrast, we can normally detect more than one process within any empirical instance of collective action. The exploration of how such processes interact with each other represents a fundamental step for the analysis.

\section{Consensus movement processes}

Coalitional networking and identities both characterize consensus movements, ${ }^{16}$ as actors share solidarity and an interpretation of the world, enabling them to link specific acts and events in a longer time perspective. However, sustained collective action does not include a conflictual element. Collective goods are often produced through cooperative efforts that neither imply nor require the identification of specific adversaries, trying to reduce the assets and opportunities of one's group or preventing chances to expand them. Problems to fight may be attributed to natural disaster, bad luck, or - when it comes to human error - to lack of information, skill, or education rather than systematic, concerted efforts by one group to mislead the others. Prospected solutions may not require redistribution of power nor alterations in social structure but focus instead on service delivery, selfhelp, personal and community empowerment. Likewise, the practice and promotion of alternative lifestyles need not include the presence of opponents defined in social and political terms. Collective actors may fight ethereal adversaries, ranging from bad or conventional taste, in the case of artistic and style-oriented movements, to "the inner enemy," in the case of some religious movements, without necessarily blaming any social actors for the state of things they intend to modify.

\section{Conflictual coalitional processes}

In these cases, collective actors are densely connected to each other in terms of alliances, and may identify opponents explicitly, but those alliances are not backed by strong identity links. The networks among actors mobilizing on a common goal take a purely contingent and instrumental nature. Resource mobilization and campaigning are then conducted mainly through exchanges and pooling of resources between distinct groups and organizations. The latter rather than the network is the main source of participants' identities and loyalties. Once a specific battle has been fought, there need not be any longer term legacy as far as identity and solidarity is concerned, nor attempts to connect the specific campaign in a broader framework. If that is the case, networks are then the expression of pure coalitional processes, where actors 
instrumentally share resources in order to achieve specific goals, yet do not develop any particular sense of belonging and of common future during the process. ${ }^{17}$ Once actors have achieved their aims - or once it has become clear they cannot reach them - the coalitional process terminates, with no further practical or ideational bonds between the parties involved in it.

\section{Consensus coalitional processes}

Similar considerations apply to cases in which resources are pooled to pursue specific practical goals, yet without a narrative placing the distinct episodes into broader frameworks, and without broader identities developing out of the action. All instances of organizations, engaging in dense networking to produce collective goods, to address practical problems, to facilitate the spread of certain lifestyles or cultural practices, without identifying any specific social or political targets, may provide illustrations of this particular process. For example, coalitions promoted by transnational humanitarian NGOs to address particular crises in some regions of the world usually act without taking on any specific opponent; the same often happens to voluntary organizations working on social exclusion when they join forces to address specific domestic issues such as homelessness under freezing winter conditions, or emergencies caused by natural forces such as floods, earthquakes, and the like. ${ }^{18}$

\section{Conflictual organizational processes}

In this model, the density of the networks linking different actors is low and the identity links between them are weak. Collective action is largely conducted within specific organizations, i.e., in the form of stable, purposive interactions between individuals or collective units, with some established membership criteria and some patterned mechanisms of coordination and internal regulation. ${ }^{19}$ Such organizations may display varying degrees of formalization and radicalization, ranging from revolutionary parties such as the Nazis or the Bolsheviks to reform-oriented ones such as those in the labor or Christian-democrat tradition, from church-related associations to public-or private-interest groups, from voluntary organizations to informal grassroots groups. Whatever their specific forms, resource mobilization and campaigning activities will be shaped by the norms and procedures established within the organizations interested in certain issues. The actors with legitimacy to mobilize will be those who do so through organizations, 
and there will be few opportunities for individuals to play any role unless their participation is mediated by specific organizations. Organizations will compete to acquire full control of their issues or at least to secure distinct niches.

\section{Consensual organizational processes}

These processes differ from other organizational processes because of the lack of a conflictual element. They are best illustrated by those innumerable instances in which services and other public goods are produced within specific organizations with little going on in terms of networking and inter-organizational exchanges. Most voluntary organizations seem to operate according to this logic most of the time. A focus on non-controversial goals or on service delivery may often - if not necessarily - result in a pattern of action where the most important ties by far are those with public representatives and agencies responsible for specific policy areas, or possibly with private sponsors. Heavy reliance on institutions, competition dynamics with other organizations or, conversely, pronounced division of labor may each contribute to reducing the relevance of alliance building between voluntary actors. ${ }^{20}$

Before illustrating how different processes may be identified in specific episodes of collective action at the local level, it is advisable to preempt some of the ambiguities and misunderstandings that the very emphasis on definitions may encourage. To begin with, insisting on conflict as a distinctive trait of movements need not force social movement analysts away from the investigation of those instances of collective action where a conflict is difficult to identify, such as those oriented to personal change and those focusing on the delivery of some kind of help or assistance to an aggrieved collectivity. Both conflictual and consensual dynamics may usually be found within the same broad phenomena. For example, although environmental action often displays a conflictual element, when it takes the form of sustained collective efforts, involving a variety of groups and organizations, attempting to protect the environment through voluntary work, or to transform environmental consciousness through education, it approximates a consensus movement process. The same often applies to those episodes of collective action usually referred to as solidarity movements. In those cases, a broad collective identity may well bring together people, organizations, events, and initiatives in meaningful, long-term collective projects, transcending the boundaries of any specific organization or campaign, but the space for conflictual dynamics may vary substantially. ${ }^{21}$ 
Nor does stressing the peculiarity of movements as informal networks rule out social movement theorists analyzing specific organizations, as suggested by some critics. ${ }^{22}$ Instead, it forces analysts to recognize explicitly, by elaborating specific concepts, the distinction between social movement processes and organizational processes. Rather than looking at groups as diverse as Common Cause or the Nazi party as "movements," applying to them the same label used for networks of multiple organizations, it will be important to use a rigorous definition of movements to identify the co-presence and interaction within each of them of both movement and (bureaucratic) organizational processes. For example, recognizing such differences enables us to specify the distinction better between the Nazi party and the Nazi movement, and to explore the interaction between the two processes. We could map the extent and the shape of the links, connecting the various right-wing and paramilitary organizations that provided in the late 1910s and 1920s the backbone of what was to become the Nazi party. ${ }^{23}$ We could then document how the NSDAP and its most directly connected organizations came to play an increasingly central role in the right-wing network. We could also illustrate how eventually formal links between the Party, its individual members, and its collateral organizations came to replace almost totally the informal links between them through (a) the definition of formal criteria for individual membership in the Party, and (b) the domination of the party over any other organization, including the SS. Far from preventing us from analyzing movements that largely overlap with a specific organization, a view of a movement as an informal network of several individuals and organizations would help us identify the tension between movement and organizational dynamics within complex empirical cases of collective action and possibly to trace its evolution over time. ${ }^{24}$

It is also important to remember that associating movements with a distinctive collective identity implies no assumptions about the homogeneity of the actors sharing that identity. ${ }^{25}$ We have a social movement identity to the extent that groups or individuals feel part of a collectivity, mobilized to support or oppose social change; that they identify shared elements in their past, present, and future experiences; and that other social or political actors be held responsible for the state of affairs being challenged. Whether a specific collective identity will be inclusive or exclusive; the degree to which holders of such identity will share one or several traits; the range of behaviors and lifestyles that will be associated with such identity, are empirical questions that may find totally different answers in different contexts. For example, 
the Italian radical left-wing movements of the 1970s seemed to be more homogenous (if far from totally homogenous) in terms of their members' orientations and lifestyles than the environmental movement that followed them in the 1980 s. ${ }^{26}$ If anything, strong similarity among individuals and organizations sharing the same exclusive identity will tend to correspond with cases in which movement dynamics tend to be weakest, such as mass parties (the already mentioned NSDAP being an excellent example) or religious sects, where the movement dynamic ends when sect members refuse to recognize any common ground with people subscribing to other cults.

\section{Exchanges, identity, and conflict in citizens' networks}

The study

We look for collective action processes within networks of organizations mobilizing on environmental, ethnic, minority, community, and social exclusion issues. These organizations provide a particularly interesting unit for the analysis of coalition-building and inter-organizational networking: they are distinct enough to work independently, yet have enough potential areas of convergence to render cross-sector alliances a feasible option (e.g., on issues such as North-South relations, peace, refugees, urban decay, racism, etc.). Between 2001 and 2002, face-to-face interviews took place with representatives of 124 organizations in Glasgow and 134 in Bristol. These included both local branches of UK-wide organizations (in Glasgow, also Scotland-wide), and independent local groups, with a varying degree of formalization and bureaucratization. All the organizations that played a city-wide role were contacted; ${ }^{27}$ as for community organizations, rather than taking a small sample from across the city, efforts were concentrated on two areas, both relatively deprived. ${ }^{28}$

Respondents were asked to identify up to five most important partners in alliances. They were also invited to identify any additional important collaboration with groups belonging to any of the following categories: environmental organizations, ethnic organizations, community organizations, churches, political parties, unions, and other economic interest groups, other voluntary organizations, other organizations. The resulting data on alliances should not be treated as a list of the groups with which our respondents exchanged most frequently or most intensely in objective terms, but of those they perceived as their most important 
allies at the time of the interview. Accordingly, the matrix of alliances, which represents the basis of our analysis, is best interpreted as an indicator of perceptions of closeness rather than objective intensity of exchange. It reflects, in other words, how organizations perceive their social space and identify their most relevant contacts within it.

\section{Inter-organizational alliances}

The overall density of the 124 actors alliance network in Glasgow is 0.023 , corresponding to $2.3 \%$ of the total number of possible ties among the organizations interviewed. In Bristol, the density of the 134 actors is slightly lower at 0.016 ( $1.6 \%$ of possible ties). Even though only a tiny proportion of possible links is activated in both cities, making sense of how inter-organizational collaborations combine in broader network patterns is no easy task. A clustering procedure ${ }^{29}$ enables us to simplify the structures and bring them down in both cases to three blocks of organizations, occupying the same structurally equivalent position: namely, identifying the same actors in the network as their closest allies. ${ }^{30}$

The distribution of density scores within and across the three structurally equivalent blocks points at some striking similarities between the Glasgow and the Bristol cases (Table 2 and Table 3). As a non-parametric test suggests, ${ }^{31}$ in both cities we can identify blocks (Glasgow 3 and Bristol 3), the incumbents of which are related to each other much more frequently than is the case across the network as a whole, and also engage with actors in other blocks relatively frequently (Figure 1). Organizations in block 3 are not only structurally equivalent following similar ties to third parties, they are also densely tied to each other. In general, organizations in block 3 are also more likely to identify organizations in other blocks as allies than to be identified as such by them.

Table 2. Densities in the interorganizational alliances network

\begin{tabular}{lccccccc}
\hline & \multicolumn{3}{c}{ Glasgow } & & \multicolumn{3}{c}{ Bristol } \\
\cline { 2 - 4 } \cline { 7 - 8 } \cline { 6 - 8 } Blocks & Glasgow 1 & Glasgow 2 & Glasgow 3 & & Bristol 1 & Bristol 2 & Bristol 3 \\
\hline 1 & 0.034 & 0.023 & 0.018 & & 0.021 & 0.011 & 0.024 \\
2 & 0.005 & 0.002 & 0.004 & & 0.006 & 0.003 & 0.013 \\
3 & 0.024 & 0.022 & 0.071 & & 0.026 & 0.012 & 0.083 \\
$N$ & 45 & 38 & 41 & & 50 & 59 & 25 \\
\hline
\end{tabular}


Table 3. Non-parametric estimates of the density of alliance ties in structurally equivalent blocks in Glasgow and Bristol

\begin{tabular}{llllll}
\hline & Glasgow & \multicolumn{3}{l}{ Bristol } \\
\hline Model fit & $R$-square & Sig. & $R$-square & Sig. \\
& 0.015 & 0.000 & 0.013 & 0.000 \\
& Stdized & & & Stdized & \\
& coefficient & Sig. & coefficient & Sig. \\
Ties within Block 1 & 0.039 & 0.004 & Ties within Block 1 & 0.023 & 0.027 \\
Ties within Block 2 & -0.027 & 0.007 & Ties within Block 2 & -0.032 & 0.000 \\
Ties within Block 3 & 0.112 & 0.000 & Ties within Block 3 & 0.105 & 0.000 \\
\hline
\end{tabular}

At the same time, we can also identify clusters of organizations (Glasgow 2 and Bristol 2; see Figure 2) whose structural equivalence depends overwhelmingly on their receiving ties from organizations located in other structural positions. As Table 3 shows, incumbency in this block is significantly and negatively correlated to the chance of having links to other organizations in the same position. The density of Block 2 is extremely low in both cities; as an average, their incumbents engage with only 0.17 groups in the same block in Glasgow and 0.22 in Bristol. Ties to organizations in other blocks are also rare in Glasgow, and only marginally more frequent in Bristol (Table 2). The dominant style of networking in these blocks sees organizations being important partners to other members of the network (particularly in Glasgow, but also in Bristol), but not particularly engaged with the network as a whole (neither internally nor externally) when it comes to identify alliance partners. This does not mean that these organizations are weakly networked in absolute terms; simply, they either work mainly with other actors (such as churches, institutions, schools, or the umbrella organizations we have deliberately excluded from this analysis) or with organizations outside the sectors covered by the survey (none of which however was mentioned as a partner more than three times).

Finally, both networks include a cluster of organizations (Glasgow 1 and Bristol 1; see Figure 3) that are linked internally by a significant number of ties (as the positive and significant coefficient in Table 3 suggests). They also engage with other blocks to a significant degree, if to a lower degree than those in block 3 . Networks within block 1 also show greater average distance between organizations. Organizations in block 3 are embedded in alliance systems such that each organization's allies are also likely to be linked to each other; where, in other words, 


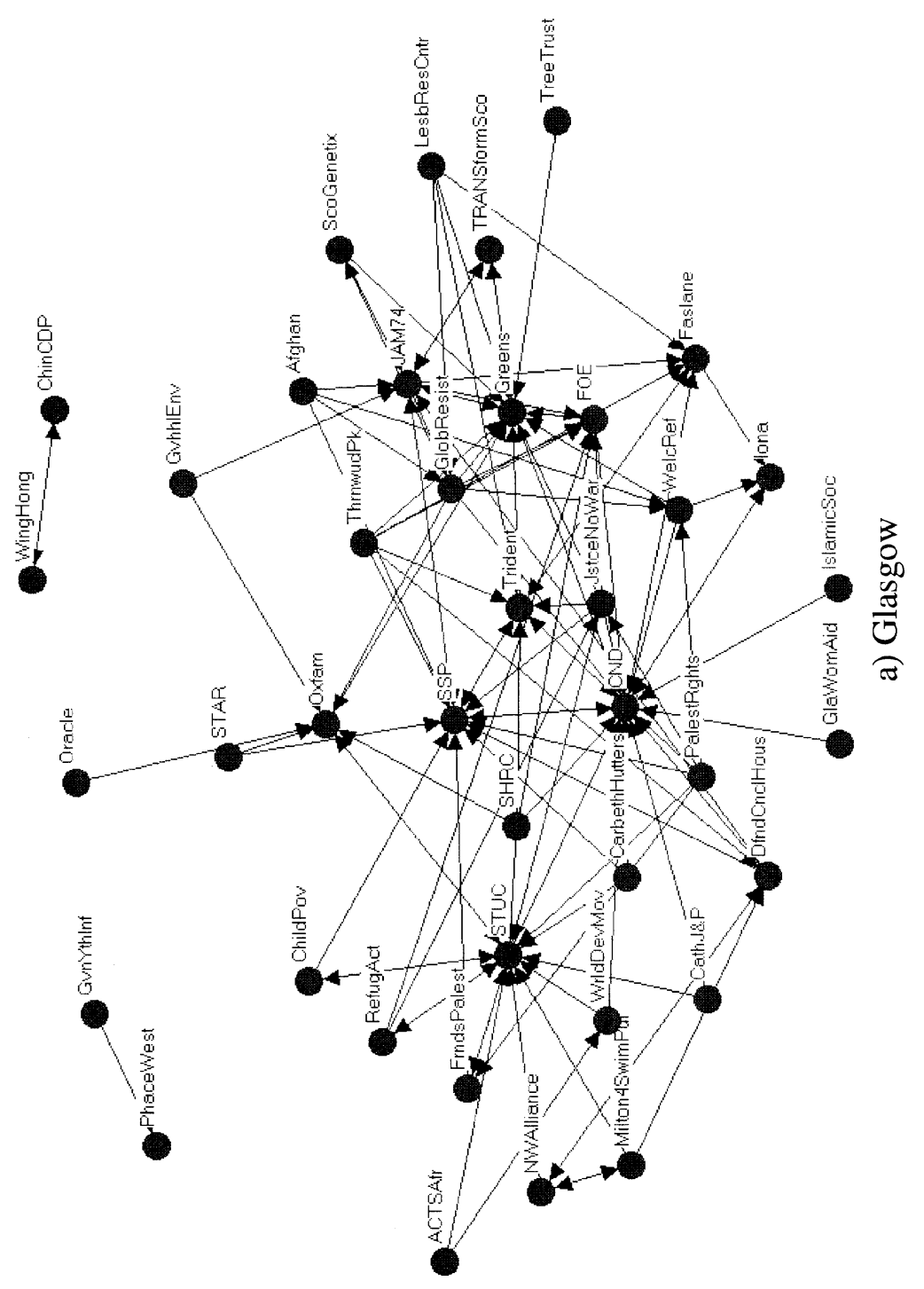




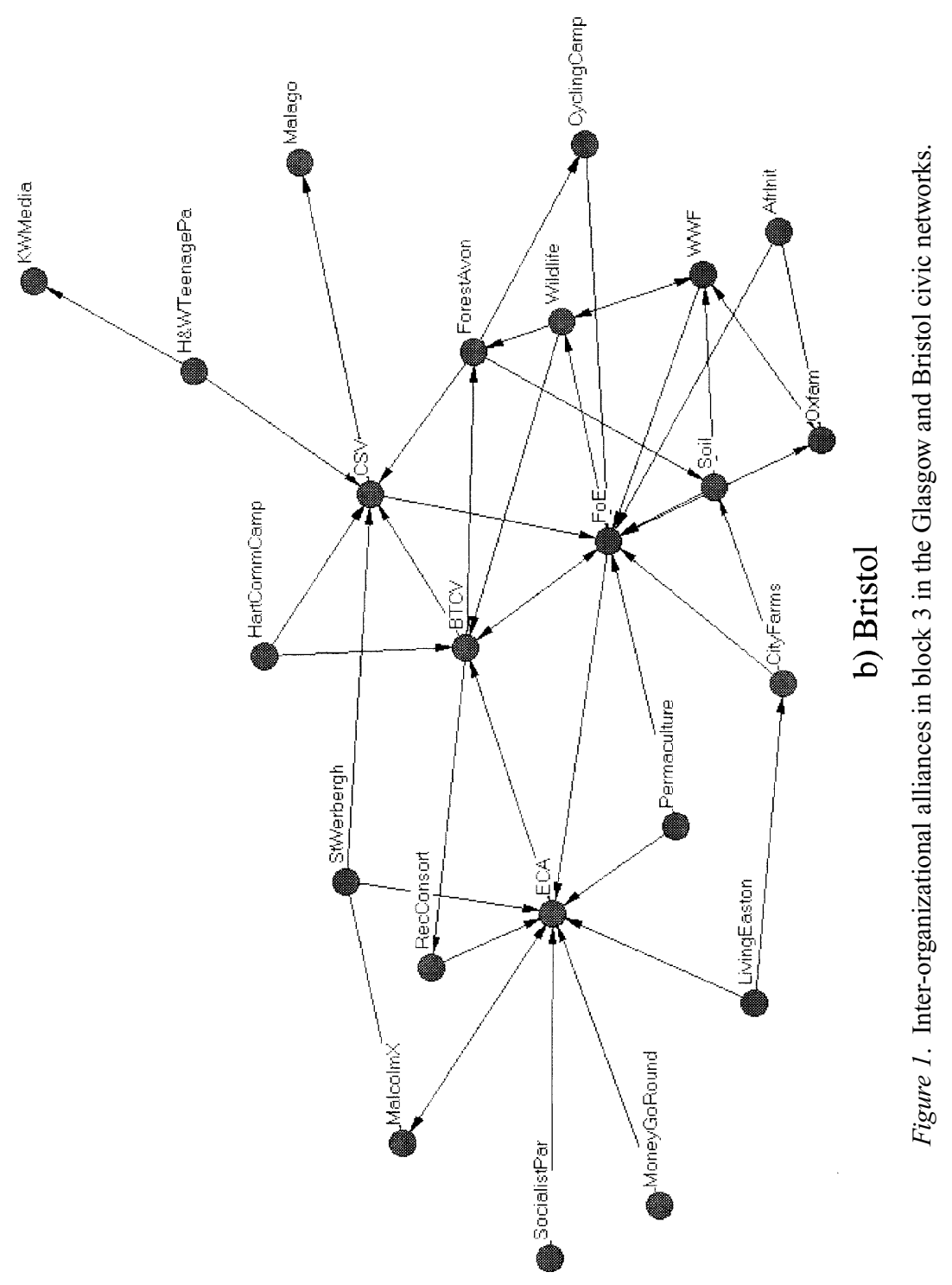




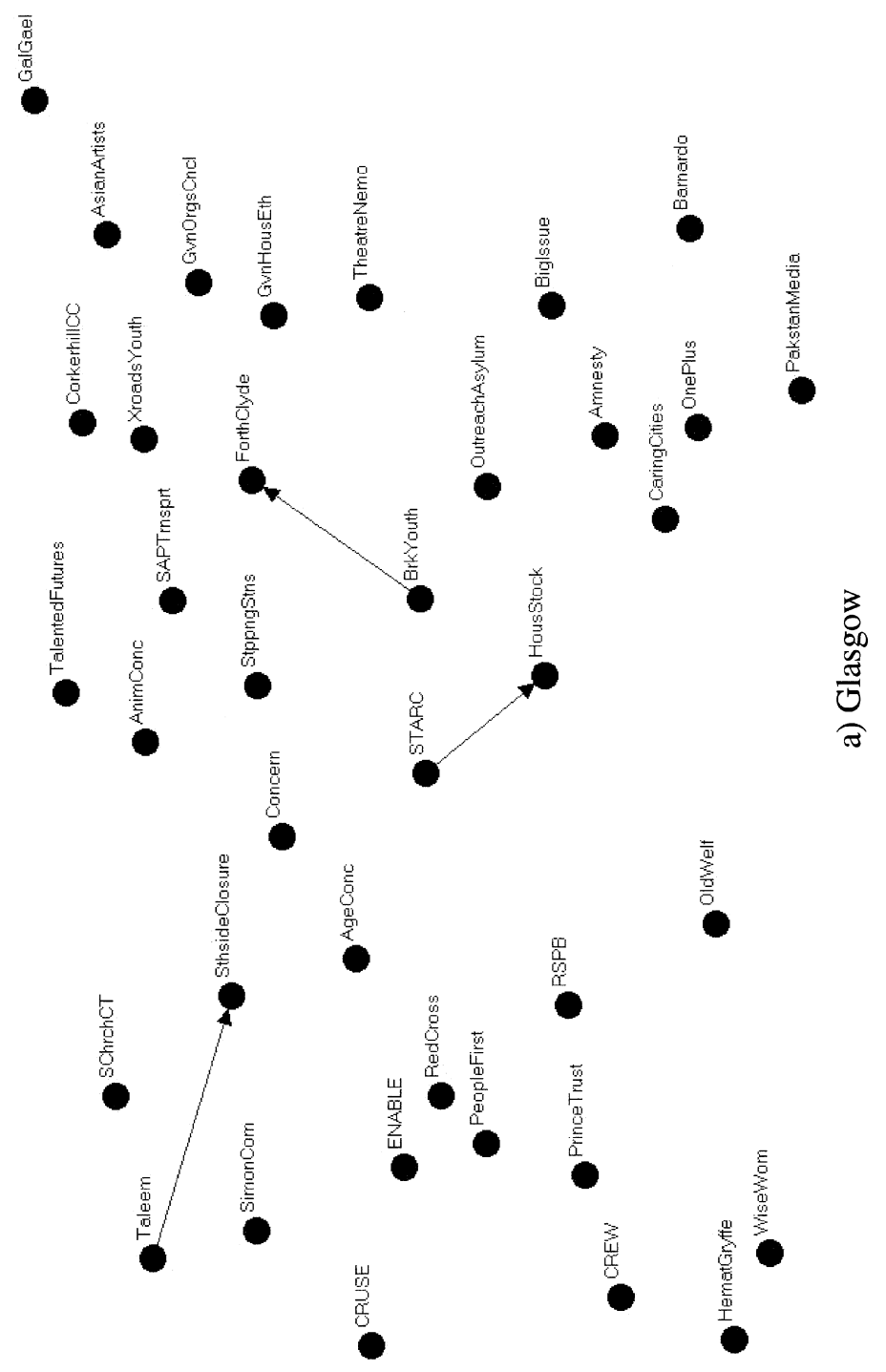




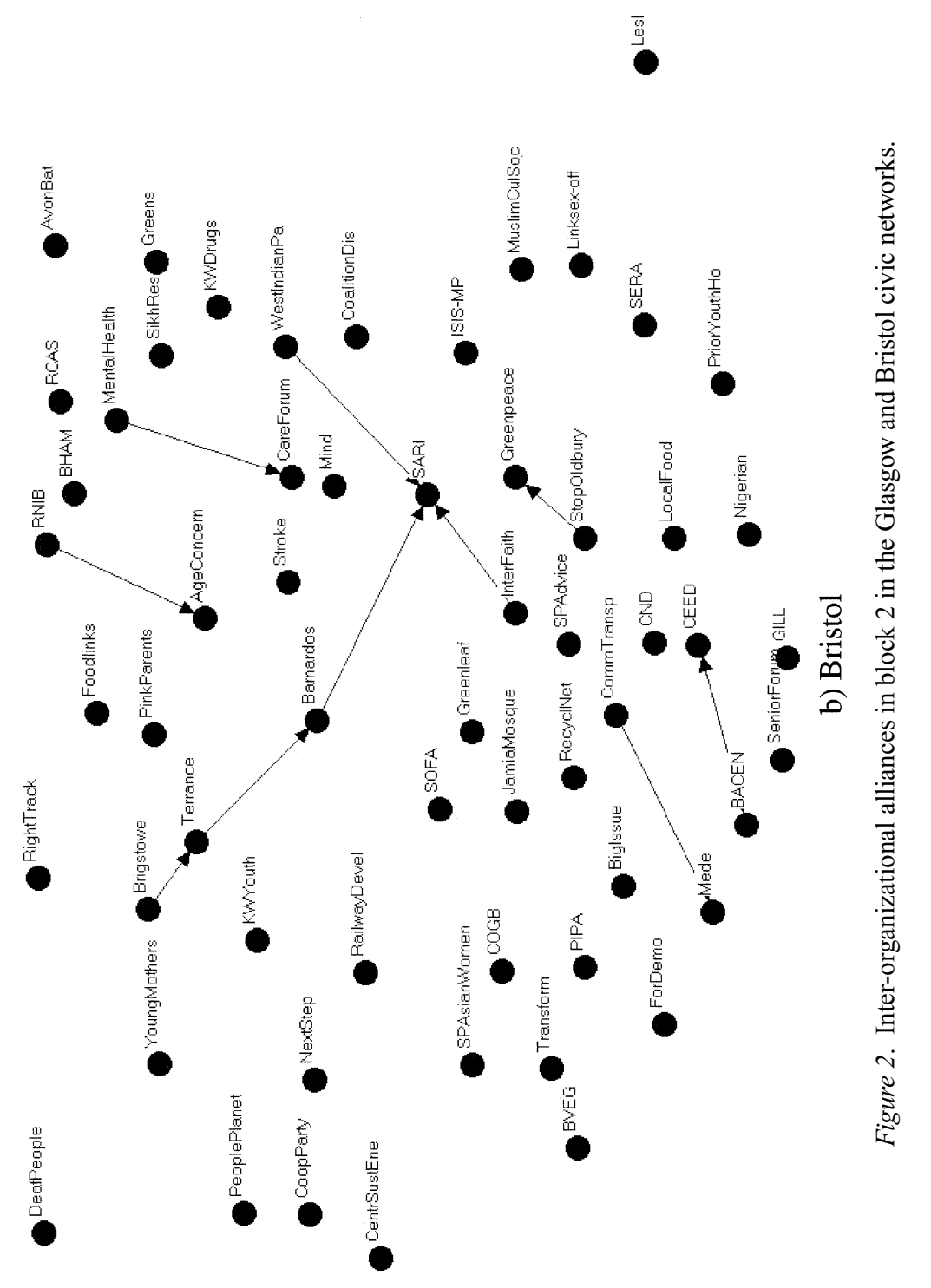




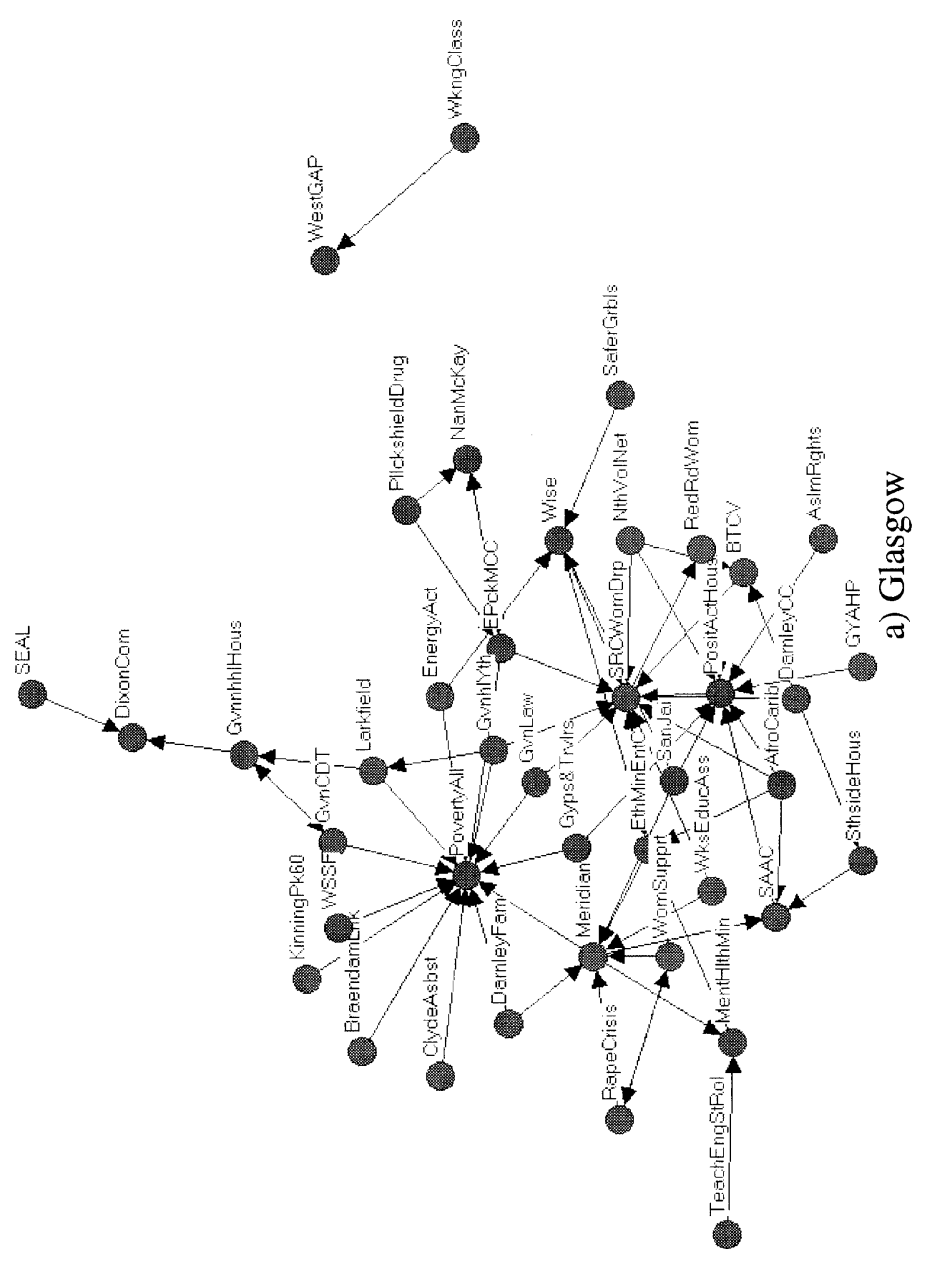




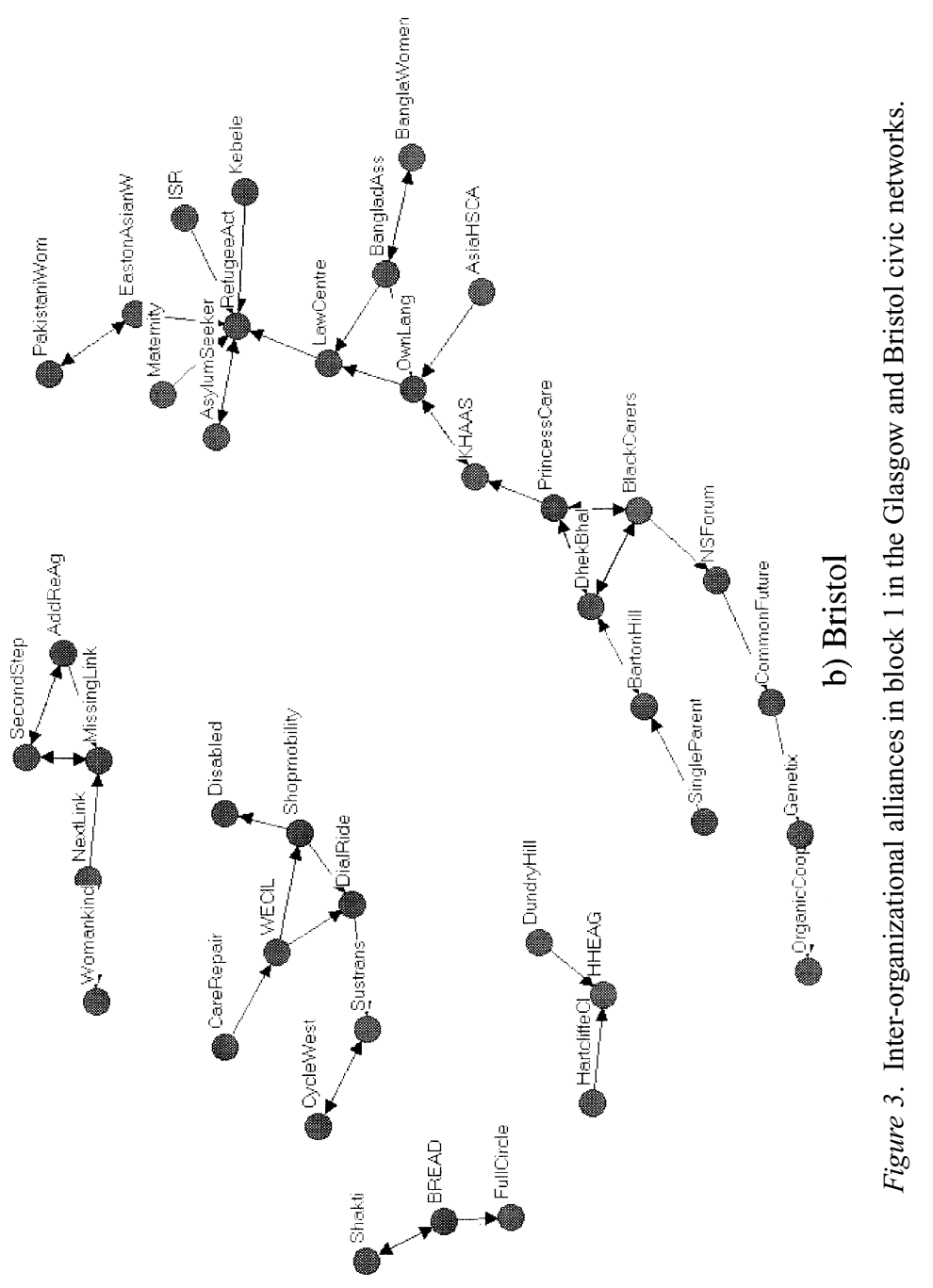


alliances seem overall fully compatible and somehow interchangeable. In block 1, in contrast, alliances rather take the form of long chains, as if they were overall more dispersed. There are also some differences between the two blocks. Bristol 1 is more segmented than Glasgow 1, having four components (rather than one) that are disconnected from the rest of the network.

The main traits of the inter-organizational alliance networks and the associated features of collective action in the two cities may be summarized as follows:

- a strongly imbalanced distribution of ties within the civic sector;

- a set of organizations (those in block 3) with a strong propensity to establish allies with organizations in the same structural position;

- another set of organizations (those in block 1) involved in a relatively dense network of ties to each other, yet inclined to spread their connections across the civic sector rather than concentrate alliances among themselves;

- a third set of organizations (the incumbents of block 2) either acting largely on their own or being regarded as important partners by others, but without reciprocating those perceptions. Although the process is more pronounced in Glasgow than in Bristol, the block density is very low in both cities by comparison to the other blocks.

If social movement processes are defined by dense networks among a plurality of actors, engaged in social conflict on the basis of a shared collective identity, then the first condition is definitely more present in blocks 1 and 3, than in block 2. To evaluate the presence of the other analytical dimensions, though, we must bring other variables into the equation.

Shared memberships, participation in public events, and collective identity

Do organizations involved in alliances also feel links to their partners, which go beyond specific initiatives or campaigns and also imply some kind of broader and long-term mutual commitment? Do they, in other words, share a collective identity? Although identity is very difficult to measure as such, we can use several indicators to test the presence of identity dynamics within a given social network. Here we focus on two of them, related to the sharing of core members between two organizations and to joint past participation in a series of public often protest - events in the two cities. First, we can test the extent of 
identity mechanisms in networks of organizations by looking at their links, based on shared core activists. Although in the case of business organizations shared personnel may simply reflect mechanisms of control, ${ }^{32}$ this is different for voluntary organizations that rest largely on solidarity incentives. There, multiple involvements provide an indicator, no matter how rough, of whether core activists perceive two organizations as compatible and close to the point of sharing their individual commitments between them. ${ }^{33}$

Second, the extent to which two organizations participated in relevant public events in their cities in the recent past tells us how much their current alliances can be regarded as the last instance of what is ultimately a string of sustained collaborations over time. By this token, it is plausible to assume that identity dynamics - in particular, that element that relates to the continuity of identification over time - are stronger, the stronger the links based on joint past participation in the same events are. To measure these links, we generated two actor-by-event matrices, recording whether organizations had taken part in any of 26 events in Glasgow and 17 events in Bristol over the last few years. These ranged from militant to institutional activities, including both grassroots action campaigns and council-supported festivals and conventions; they covered each of the thematic areas of interest to our project, from environmentalism to ethnic minorities to social exclusion. In both cities a link was recorded between two organizations if they had participated in at least three of the events listed. ${ }^{34}$

In the light of these criteria we checked to what extent the distribution of identity ties across the three blocks (Table 4), defined in reference to alliance ties, matched the distribution of the latter. We applied the same test used for alliances to identity linkages, consisting of the combination

Table 4. Densities in the identity network (shared activists or joint participation in past events)

\begin{tabular}{lccccccc}
\hline & \multicolumn{3}{c}{ Glasgow } & & \multicolumn{3}{c}{ Bristol } \\
\cline { 2 - 4 } \cline { 7 - 8 } Blocks & Glasgow 1 & Glasgow 2 & Glasgow 3 & & Bristol 1 & Bristol 2 & Bristol 3 \\
\hline 1 & 0.049 & 0.027 & 0.083 & & 0.058 & 0.042 & 0.109 \\
2 & 0.027 & 0.009 & 0.041 & & 0.040 & 0.025 & 0.078 \\
3 & 0.084 & 0.043 & 0.246 & & 0.106 & 0.075 & 0.208 \\
$N$ & 45 & 38 & 41 & & 50 & 59 & 25 \\
\hline
\end{tabular}


Table 5. Non-parametric estimates of the density of identity ties (on the basis of shared activists or joint participation in past events) in structurally equivalent blocks in Glasgow and Bristol

\begin{tabular}{llllll}
\hline & Glasgow & & \multicolumn{3}{l}{ Bristol } \\
\hline Model fit & $R$-square & Sig. & $R$-square & Sig. \\
& 0.062 & 0.000 & 0.017 & 0.000 \\
& Stdized & & & Stdized & \\
& coefficient & Sig. & coefficient & Sig. \\
Ties within Block 1 & -0.003 & 0.505 & Ties within Block 1 & -0.010 & 0.400 \\
Ties within Block 2 & -0.049 & 0.036 & Ties within Block 2 & -0.064 & 0.005 \\
Ties within Block 3 & 0.238 & 0.000 & Ties within Block 3 & 0.108 & 0.001 \\
\hline
\end{tabular}

of ties based on joint members with ties based on joint participation in important public events in the two cities in the recent past (Table 5). ${ }^{35}$ Given the difficulty to establish how dense collective identity links should be to qualify as "strong," we decided to regard identity in a given structural position as strong when the density of identity links in that position exceeded significantly the average distribution of such links in a given city.

Network patterns emerging from the analysis are entirely consistent across the two cities, and mostly consistent with those found for the alliance network. In both Glasgow and Bristol, similarly to what happened in the case of alliances, organizations located in block 2 are significantly unlikely to have identity links to each other; if they have some connection through shared members or their history of activism in the city, that is likely to be with groups who occupy a different position in alliance patterns. From the point of view of our typology, the coupling of low involvement in both alliance networks and identity networks suggests block 2 to be most closely characterized by what we called organizational processes. In contrast, and again analogously to the pattern that emerged from the alliance network, organizations in block 3 show significant, positive inclinations to share identity links with organizations in the same position. Following our logic of analysis, the combination of dense alliance networks and dense identity networks suggests the chance of movement processes going on in block 3 is high in both cities. ${ }^{36}$ The only but important difference to the pattern identified for the alliance network lies in the distribution of identity ties among incumbents of block 1. In both Glasgow and Bristol, the significantly high density of ties within the position satisfied our first criterion for a social movement dynamic. However, in both cities organizations 
in block 1 do not appear significantly connected by identity ties (Table 5). The lack of a match between dense alliance networks and identity networks suggests that, in that case, coalitional processes are taking place rather than movement ones.

\section{Conflict networks}

We also have to take into account that the structure of civic networks in Glasgow and Bristol reflects deep differences in the extent of conflictual orientations, both within and across the two cities. When asked about their two most important initiatives in the last few years, organizations were also invited to indicate whether such actions implied a conflict with some public or private actors. The former included national and local government as well as other public agencies, international and supranational institutions, etc.; the latter, specific social groups, whether defined along class, ethnic, gender, or other lines. In both cities, about one quarter of respondents' main initiatives targeted specific public actors, about one eighth targeted private actors. However, the distribution of responses across blocks partially differs in the two cities (Table 6). In both Glasgow and Bristol, organizations in block 3 - the likeliest candidates to social movement status because of their network density - were significantly more inclined to identify specific public opponents, than organizations in blocks 1 and 2. In Bristol, however, organizations in block 3 did not stand out in terms of their conflict orientations to private actors. Not only that, overall, the propensity to identify specific opponents was more evenly spread in Bristol than in Glasgow, where a deep gap separated in particular organizations in block 3 from the others.

Table 6. Percentage of groups identifying public authorities and/or specific social groups as opponents in their main initiatives

\begin{tabular}{|c|c|c|c|c|c|c|c|c|}
\hline & \multicolumn{4}{|c|}{ Glasgow } & \multicolumn{4}{|c|}{ Bristol } \\
\hline & Glasgow & Glasgow & Glasgow & & Bristol & Bristol & Bristol & \\
\hline & 1 & 2 & 3 & Total & 1 & 2 & 3 & Total \\
\hline $\begin{array}{l}\text { Public } \\
\text { authorities }\end{array}$ & $17.8 \%$ & $5.3 \%$ & $48.8 \%$ & $24.2 \%$ & $24 \%$ & $22 \%$ & $44 \%$ & $26.9 \%$ \\
\hline $\begin{array}{l}\text { Specific } \\
\text { social } \\
\text { groups }\end{array}$ & $11.1 \%$ & $5.3 \%$ & $24.4 \%$ & $13.7 \%$ & $10 \%$ & $15.3 \%$ & $12 \%$ & $12.7 \%$ \\
\hline$N$ & 45 & 38 & 41 & 124 & 50 & 59 & 25 & 134 \\
\hline
\end{tabular}


Patterns of collective action: A relational typology

The data in the previous section clearly suggest that networks of interorganizational alliances do not tell the whole story when it comes to analyzing collective action processes. Similar densities in alliances may correspond to quite different network structures if we look at other links, such as those based on past events or joint memberships. Taking those differences into account, as well as the varying weight of conflictual orientations in organizations' activities, we can identify in the two cities three out of the six processes we introduced earlier:

- Social movement processes are most clearly illustrated by block 3 in Glasgow and - to a large extent - in Bristol. There, interorganizational ties more frequently coincide with links, created by participation in past events, or by joint activists. The relational dimension stretches beyond collaborations among organizations, which might in themselves also be purely instrumental, to suggest bonds and shared identities, which secure continuity to the network. This pattern also matches conflictual orientations, particularly in Glasgow, where both social and political opponents are identified - in Bristol, the movement dynamic seems to take a distinctively political rather than social emphasis.

- Consensus coalitional processes. In block 1 in Glasgow and block 1 in Bristol, a fairly dense web of alliances finds little correspondence in ties, which more explicitly point at the presence of identity links. The gap between organizational exchanges and those links, measuring continuity of commitment over time and activists' personal involvement, is indeed particularly pronounced. Networking is limited to collaboration on specific issues. Coalitional dynamics seem to be operating there, but little can be found in the form of social movement relational processes. Organizations in this block also seem reluctant to recognize conflictual elements in their action.

- Consensus organizational processes. These are best illustrated by block 2 in Glasgow and in Bristol, where networking within the civic sector and within the position is weak, and organizations seem to hold a largely non-conflictual identity. Links between organizations are modest, however measured. Density is consistently low by comparison to the other blocks, as to suggest that the main focus for organizations in those blocks is organizational activities per se rather than the development of links to other actors occupying similar structural positions. They are not involved in distinctive sets of 
alliances, nor are they linked by connections implying some level of collective identity with other groups. In their case, structural equivalence seems to depend largely on those organizations being identified by others as relevant partners in alliances; but their overall involvement in the network is limited. Organizations in that position are also markedly reluctant to recognize a conflictual dimension to their action. The propensity to identify specific targets is particularly low, especially with reference to public actors. To summarize, the relational and the contentious dimensions of social movement action are both distinctly absent here.

\section{Conclusions}

Our characterization of social movements, although broadly inspired by current dominant approaches, cannot be reduced to any of them. On the one hand, it differs from visions of movements, which recognize the network dimension, yet emphasize mainly its interpersonal, small group element, to the detriment of the organizational and coalitional element. ${ }^{37} \mathrm{~A}$ social movement process is occurring to the extent that long-term bonds and shared identities translate into sustained networks between independent actors - most frequently organizations, although one cannot rule out in principle the role of individual activists - in pursuit of shared goals. Otherwise, what we have are countercultural or sub-cultural processes, that the corresponding concepts ${ }^{38}$ do a better job of analyzing. As suggested by work on, among others, American feminism, British environmental direct action, Italian environmentalism, ${ }^{39}$ constant attention has to be paid to the interplay of interpersonal and inter-organizational networks.

At the same time, viewing social movements as a particular form of network organization ${ }^{40}$ assigns networks a more central role than advocates of the "classic social movement agenda" (i.e., of the "political process' and "resource mobilization" perspectives) seem prepared to concede. For those subscribing to Tilly's definition of movements, a social movement is first of all a specific form of contention, sustained, national - or at least non-local - in scope, based on a modular repertoire of collective action. ${ }^{41}$ Networks and organizations are either the precondition or the outcome of a movement - or both. For the approach presented in this article, network processes - better, a specific type of network processes - are the movement. Indeed, movement action has to do as much with the constant redefinition of identity and 
solidarity links between actors - i.e., with the drawing and re-drawing of network boundaries - as with challenges to powerholders. ${ }^{42}$ The purposive, goal-oriented element of collective action, reflected in coalition networks, is supported by, and intertwines with, longer term identifications and bonds. Failing to recognize the coupling of alliance and identity networks implies blurring the boundaries between coalitional and social movement processes - which can both sustain "interactions with power-holders." In contrast, our approach highlights the substantial differences, running behind coalition work that on face value could all be brought under the same, vague, heading of "movement networking."

If networks are movements, an obvious development of this research program consists of asking whether and to what extent the processes identified here match those traits and orientations of social movement actors that analysts have traditionally focused on. In particular, to what extent does our typology differ from conventional ones, contrasting social movements to interest groups, which are apparently the equivalent to our "organizational processes"? If the homophily principle leads us to expect some overlap of structural positions and actors' categorical traits, ${ }^{43}$ a total overlap would render the whole exercise proposed here purely academic - if not deprived of some confirmatory value. To explore this issue, we should ask whether organizations involved in social movement relational process also differed significantly in action repertoires (consistently with views of protest as a distinctive trait of social movements), ${ }^{44}$ organizational forms (with social movements more likely to consist of loosely structured, grassroots organizations), ${ }^{45}$ relationships with authorities (with social movements as anti-institutional phenomena) ${ }^{46}$ and opinions (with social movements as carriers of critical beliefs and anti-institutional orientations). ${ }^{47}$ So far, preliminary explorations of our data confirm some widely held assumptions, yet qualify others significantly. They suggest in particular that the correlation between organizational properties or inclination to protest and our three processes is far from perfect, as social movement processes do not appear necessarily as the domain of loosely structured, protest-prone organizations. ${ }^{48}$

Exploring the matching of actors' traits and structural properties would also enable us to address another question raised by our findings, concerning the configuration of social movement and other collective action processes in different political settings. Glasgow and Bristol are usually regarded as very different in terms of political history, degree of radicalism in local politics, shape of local cleavages, as well as class 
composition and recent patterns of urban transformation. ${ }^{49}$ Yet the configuration of networks in the two cities presents remarkable similarities. It might be interesting then to map the substantive characteristics of the actors who occupy similar structural positions in order to check whether and how local political cultures and local political milieus affect the network organization of grassroots politics and volunteering.

Differentiating between conflictual and consensual processes, and among movement, coalitional, and organizational processes, is particularly important at a time when the use of the expression "social movement" seems to be increasingly limited to the identification of empirical episodes from which one should then extract specific processes and mechanisms. ${ }^{50}$ Although there is a lot to recommend the strategy of searching for mechanisms across a broad range of instances of political contention, there are also good reasons to recognize in social movements a specific social process, and to develop around such recognition a distinctive research program. ${ }^{51}$ Far from restricting unduly the domain of social movement research, a focus on networks as a form of social organization, and a closer integration of analytical work on concepts and empirical research, may actually expand the potential of dialogue between different social science communities. At the same time, it may give social movement research a distinct theoretical, rather than merely empirical, focus.

\section{Acknowledgments}

This article originates from an investigation of "Networks of civic organizations in Britain," that Mario Diani conducted with Isobel Lindsay (University of Strathclyde in Glasgow) and Derrick Purdue (University of West of England, Bristol) from 2000-2003. The project was part of the Democracy and Participation Program, funded by the Economic and Social Research Council (contract L215 25 2006), and directed by Paul Whiteley. Mario Diani is grateful to Paul for his constant support, to Juliana Mackenzie for her assistance with data entry and data collection in Glasgow, and to Derrick Purdue and his collaborators at UWE for their work on data collection in Bristol. Preliminary versions were presented at the conference "Contentious Politics and the Economic Opportunity Structure," University of Crete, Rhetimno, 1719 October, 2002, the annual "Democracy and Participation Conference," University of Essex, 17-19 January 2003, and the "Democracy and Participation Panel" at the European Sociological Conference, 
Murcia, 24 September 2003. We are indebted to Delia Baldassarri, Donatella della Porta, Fiona Devine, Brian Doherty, Ruud Koopmans, Maria Kousis, Debra Minkoff, Christopher Rootes, Charles Tilly, and Alan Warde, for their comments and insights. Most of all, however, we are indebted to members of civic organizations in Glasgow and Bristol, for their invaluable collaboration. For the record, Mario Diani wrote the first and third sections; Ivano Bison wrote the second.

\section{Notes}

1. Charles Tilly, "Social Movements as Historically Specific Clusters of Political Performances," Berkeley Journal of Sociology 38 (1994): 1-30.

2. Doug McAdam, Sidney Tarrow, and Charles Tilly, Dynamics of Contention (Cambridge: Cambridge University Press, 2001).

3. Charles Tilly, "Agendas for Students of Social Movements," in Jack Goldstone, editor, States, Parties, and Social Movements (Cambridge: Cambridge University Press, 2003), 248.

4. Doug McAdam, Sidney Tarrow, and Charles Tilly, Dynamics of Contention, 76.

5. Or, in Doc's language, "competition," "identity shift," "opportunity spirals,", to mention just a few (Doug McAdam, Sidney Tarrow, and Charles Tilly, Dynamics of Contention, 252-253).

6. Mario Diani, "The Terrestrial Emporium of Contentious Knowledge," Mobilization 8 (2003): 109-112.

7. Mario Diani, "The Concept of Social Movement," Sociological Review 40 (1992): 13.

8. Mario Diani, "The Concept of Social Movement"; Mario Diani, "Networks and Social Movements: A Research Program," in Mario Diani and Doug McAdam, editors, Social Movements and Networks: Relational Approaches to Collective Action (Oxford: Oxford University Press, 2003), 299-319.

9. On these issues see, among many others, William Gamson, "The Social Psychology of Collective Action," in Aldon Morris and Carol McClurg Mueller, editors, Frontiers in Social Movement Theory (New Haven: Yale University Press, 1992), 53-76; Alberto Melucci, Challenging Codes (Cambridge: Cambridge University Press, 1996), Part I.

10. Alberto Melucci, Nomads of the Present (London: Hutchinson Radius, 1989); Alberto Melucci, Challenging Codes.

11. Alessandro Pizzorno, "Decisioni o Interazioni? La Micro-descrizione del Cambiamento Sociale," Rassegna Italiana di Sociologia 37 (1996): 107-132.

12. Alain Touraine, The Voice and the Eye. An Analysis of Social Movements (Cambridge: Cambridge University Press, 1981).

13. Alberto Melucci, Challenging Codes; Manuel Castells, The Information Age: Economy, Society and Culture. Vol. II: The Power of Identity (Oxford: Blackwell, 1997).

14. Alberto Melucci, Challenging Codes, Chap. 3.

15. The combination of three dichotomous variables actually generates eight possible cases. We ignore for the time being those types in which a strong movement identity combines with sparse informal networks, i.e., with a style of collective 
action conducted mainly within organizations. Their capacity to capture empirical instances of collective action seems limited to us.

16. We see consensus movements as forms of collective action that "are distinguished from conflict movements in terms of the degree to which each recognizes and acts on oppositions of objective social interests and seeks in direct and detailed fashion to change social policy" (John Lofland, "Consensus Movements: City Twinnings and Derailed Dissent in the American Eighties," Research in Social Movements, Conflict and Change, 11 [1989], 163). We prefer this analytical definition to others, simply taking the proportion of people supporting a given cause as the defining element (John McCarthy and Mark Wolfson, "Consensus Movements, Conflict Movements, and the Cooptation of Civic and State Infrastructures," in Aldon Morris and Carol McClurg Mueller, editors, Frontiers In Social Movement Theory (New Haven: Yale University Press, 1992), 274.

17. Barbara Hinckley, Coalitions and politics (New York: Harcourt Brace Jovanovich, 1981), 4-5; Vincent Lémieux, "Reseaux et coalitions," L'Année Sociologique 47 (1997): 55-72. Of course, nothing prevents a coalitional dynamic from evolving into a social movement one (see, e.g., Mark Warren, "Power and conflict in social capital. Community organizing and urban policy," in Bob Edwards, Michael Foley, and Mario Diani, editors, Beyond Tocqueville [Hanover: University Press of New England, 2001], 169-182). However, it is still important to recognize the analytical difference between the two processes.

18. See, e.g., Mary Kaldor, "A Decade of Humanitarian Intervention: The role of global civil society," in Helmut Anheier, Marlies Glasius, and Mary Kaldor, editors, Global Civil Society (Oxford: Oxford University Press, 2001), 109-145.

19. This definition is closest to what Richard Scott (Organizations [Englewood Cliffs, NJ: Prentice Hall, 1987], 10) classically refers to as the rational system perspective, according to which "organizations are collectivities oriented to the pursuit of relatively specific goals and exhibiting relatively high formalized social structures."

20. See, e.g., Jeremy Kendall and Martin Knapp, The Voluntary Sector in the UK (Manchester: Manchester University Press, 1996).

21. See, e.g., Giorgio Osti, La natura, gli altri, la societa : Il terzo settore per L'ambiente in Italia (Milan: Angeli, 1998); Marco Giugni and Florence Passy, editors, Political Altruism? (Lanham, MD: Rowman and Littlefield, 2001).

22. Chris Pickvance, "Social Movements in the Transition from State Socialism: Convergence or Divergence," in Louis Maheu, editor, Social Movements and Social Classes: New Actors and New Agendas (London: Sage, 1995), 146.

23. Helmut Anheier, "Movement Development and Organizational Networks: The Role of 'Single Members' in the German Nazi Party, 1925-1930," in Mario Diani and Doug McAdam, editors, Social Movements and Networks: Relational Approaches to Collective Action (Oxford: New York: Oxford University Press, 2003), 49-74.

24. A logic of investigation that, incidentally, may also be conveniently applied to the formation of many contemporary parties: see Angelo Panebianco, Political Parties (Cambridge: Cambridge University Press, 1988); Peter Hedström, Rickard Sandell, and Charlotta Stern, "Mesolevel Networks and the Diffusion of Social Movements: The Case of the Swedish Social Democratic Party," American Journal of Sociology 106 (2000): 145-172. 
25. As suggested among others by Christopher Rootes, "Environmental protest in Britain 1988-1997," in Ben Seel, Matthew Paterson, and Brian Doherty, editors, Direct Action in British Environmentalism (London: Routledge, 2000), 26-61.

26. Robert Lumley, States of Insurgency (London: Verso, 1990); Mario Diani, Green Networks (Edinburgh: Edinburgh University Press, 1995).

27. There are strong reasons to believe that, with the exception of one ethnic organization in Bristol, all the most central organizations in the two cities were contacted: Although many other organizations, which were not among those interviewed, were mentioned by respondents, none received more than three nominations (the $10 \%$ most central organizations in the two cities were named seven times or more by other network members).

28. These were the Southside in Glasgow, an area with massive historical presence of working class, including neighborhoods such as Govan, Govanhill, Gorbals, and Pollokshields; and the area including the neighborhoods of Easton, Knowles, Withywood, and Hartcliffe in Bristol, featuring a strong presence of ethnic minorities.

29. We used Concor, a procedure developed by Ronald L. Breiger, Scott A. Boorman, and Philip Arabie ("An Algorithm for Clustering Relational Data with Application to Social Network Analysis and Comparison with Multidimensional Scaling," Journal of Mathematical Psychology 12 [1975]: 328-383). Many have pointed out the ambiguous nature of the computation through which Concor generates its partition of a network, most forcefully Stan Wassermann and Katherine Faust (Social Network Analysis [New York: Cambridge University Press, 1994], 380381). However, it has also been remarked how it tends to generate substantively interpretable results (David Knoke and James H. Kuklinski, Network Analysis [London/Newbury Park, CA: Sage, 1982], 74), and how its result are most problematic in the case of graphs consisting of different components (John Scott, Social Network Analysis. A Handbook [London/Newbury Park, CA: Sage, 1991], 140), which is not the case here.

30. For a more formal definition of structural equivalence, see Stan Wassermann and Katherine Faust, Social Network Analysis, 356-361.

31. We used a test of autocorrelation for categorical variables in order to allow for the lack of independence between cases. The procedure enabled us to test whether organizations were more likely to identify as allies or to have identity links with organizations occupying the same structural position - i.e., located in the same block - rather than with other groups. In particular, we used the procedure indicated as "Network autocorrelation with categorical variables" in Ucinet 6 (Steven Borgatti, Martin Everett, and Linton Freeman, Ucinet 6 for Windows: Software for Social Network Analysis [Harvard: Analytic Technologies, 2002]).

32. Mark Mizruchi and Michael Schwartz, editors, Intercorporate Relations. The Structural Analysis of Business (Cambridge/New York: Cambridge University Press, 1987).

33. Considering that the presence of joint core members was recorded only between organizations who identified each other as a most important ally, the density of the resulting networks is unsurprisingly very low, 0.005 in Glasgow and 0.010 in Bristol.

34. This time, the density of the resulting networks was - once again, unsurprisinglyhigher than in the inter-organizational alliance networks ( 0.065 in Glasgow and 0.054 in Bristol). 
35. We also ran the same procedure separately on the networks consisting of ties of shared memberships and joint participation in past events, with similar results.

36. A preliminary inspection of the data, based on a generalized loglinear model, confirmed findings about Glasgow but could not find evidence of a strong overlap of alliance and identity link in Bristol block 3. Although we are confident that the procedure adopted here is the most appropriate for this type of data, care should be taken when interpreting the Bristol findings until further examination of the data is conducted.

37. Alberto Melucci, Challenging Codes, 113-117.

38. Milton J. Yinger, "Contraculture and subculture," American Sociological Review 25 (1960): 625-635.

39. See, respectively, Nancy Whittier, Feminist Generations: The Persistence of the Radical Women"s Movement (Philadelphia: Temple University Press, 1995); Brian Doherty, Studying Local Activist Communities Over Time: Direct Action in Manchester, Oxford and North Wales, Paper for the 6th European Socioloogical Conference, Murcia, September 2003; Mario Diani, Green Networks.

40. Ranjay Gulati and Martin Gargiulo, "Where Do Inter-organizational Networks Come From?" American Journal of Sociology 104 (1999): 1439-1493; Patrick Kenis and David Knoke, "How Organizational Field Networks Shape Interorganizational Tie-Formation Rates," Academy of Management Review 27 (2002): 275-293; Mario Diani, "Networks and Social Movements: A Research Program."

41. Charles Tilly, "Agendas for Students of Social Movements," 248.

42. Recent work by Tilly addresses this issue yet - as far as we are aware - without systematic connection to social movement processes (Charles Tilly, Social Boundary Mechanisms, unpublished article, Columbia University, 2003).

43. Miller McPherson, Lynn Smith-Lovin, and James M. Cook, "Birds of a Feather: Homophily in Social Networks," Annual Review of Sociology 27 (2001): 415-444.

44. Dieter Rucht, "Parties, Associations and Movements as Systems of Political Interest Intermediation," in Josef Thesing and Wilhelm Hofmeister, editors, Political Parties in Democracy (Sankt Augustin: Konrad-Adenauer-Stiftung, 1995), 103125.

45. Alberto Melucci, Challenging Codes; Hanspeter Kriesi, "The Organizational Structure of New Social Movements in a Political Context," in Doug McAdam, John D. McCarthy, and Mayer N. Zald, editors, Comparative Perspectives on Social Movements (Cambridge/New York: Cambridge University Press, 1996), 152-184.

46. Alberto Melucci, Challenging Codes.

47. Russell Dalton, Citizen Politics in Western Democracies (Chatham, NJ: Chatham House, 1996); Pippa Norris, Democratic Phoenix (New York/Cambridge: Cambridge University Press, 2002).

48. Mario Diani, Isobel Lindsay, and Derrick Purdue, Networks of Citizens' Organizations in Britain: Report of Main Findings, Research Report, Department of Government, University of Strathclyde in Glasgow, December 2003.

49. Derrick Purdue and Mario Diani, Voice and Leadership in Civic Networks in Bristol (and Glasgow), paper for the "Voice, Leadership and Accountability Conference," Centre for Local Democracy, University of the West of England, 8-10 September 2003.

50. Doug McAdam, Sidney Tarrow, and Charles Tilly, Dynamics of Contention.

51. Mario Diani, "Networks and Social Movements: A Research Program." 